\title{
Immunogenicity of recombinant hepatitis $B$ vaccine: comparison of two different vaccination schedules
}

\author{
S. Agladioglu $\cdot$ U. Beyazova $\cdot$ A. D. Camurdan • \\ F. Sahin • A. Atak
}

Received: 11 February 2010/ Accepted: 3 May 2010/Published online: 29 May 2010

(C) The Author(s) 2010. This article is published with open access at Springerlink.com

\begin{abstract}
Background Neonatal immunization with hepatitis B (HB) vaccine induces protective levels of antibody (anti$\mathrm{HBs} \geq 10 \mathrm{IU} / \mathrm{L}$ ) in a majority of vaccines. However, the duration of protection after $\mathrm{HB}$ vaccination in infants is unknown. A smaller proportion of children vaccinated beginning at birth with three doses of $\mathrm{HB}$ vaccine were found to have protective titers 5-10 years after initial vaccination. Long-term efficacy of $\mathrm{HB}$ vaccine depends mainly on peak antibody levels after vaccination, and subjects were observed to have lower levels of antibodies if they received the first dose of vaccine immediately after birth. The aim of our study was to compare the immunogenicity of two different HB vaccine schedules in infants born to HB surface antigen-negative mothers.

Methods Anti-HBs titers in infants vaccinated with two different schedules were compared. Infants were vaccinated at 0,2 , and 9 months (group 1) or at 2, 4, and 9 months (group 2). In total, 267 blood samples were analyzed at a mean of $14.20 \pm 2.39$ months after the third vaccine dose. Sera were tested for hepatitis B surface antigen (HBsAg), hepatitis B surface antibody (anti-HBs), and hepatitis B core antibody (anti-HBc) using commercial enzyme immunoassay kits.

Results The geometric mean titers for anti-HBs were 95.00 and $379.51 \mathrm{IU} / \mathrm{L}$ and the rates of anti-HBs more than $\geq 100 \mathrm{IU} / \mathrm{L}$ were 57.7 and $94.9 \%$ in group 1 and 2 infants, respectively.
\end{abstract}

S. Agladioglu · U. Beyazova · A. D. Camurdan $(\bowtie)$.

F. Sahin · A. Atak

Gazi University Medical Faculty, Ankara, Turkey

e-mail: aysucamurdan@yahoo.com
Conclusion Delaying the first dose of the HB vaccine until 2 months after birth produces a higher immune response and can provide longer term protection.

Keywords Hepatitis B vaccine - Immunity duration · Immunogenicity $\cdot$ Schedules

\section{Introduction}

Safe and effective vaccines against hepatitis B (HB) infection have been available since 1982. The World Health Organization (WHO) recommends universal vaccination against $\mathrm{HB}$ to ultimately eliminate $\mathrm{HB}$; this recommendation had been progressively implemented, with 168 countries having with a universal immunization program by the end of 2006 [1].

Neonatal vaccines have certain medical advantages, namely, they produce early protection for the vulnerable newborn period, and there is the advantage of birth cohort accessibility. However, newborns do have impaired immune responses due to a range of deficiencies in both adaptive immunity and innate immunity as well as the potentially suppressive effects of maternally derived antibodies [2].

The duration of protection after HB vaccination of infants vaccinated at birth is unknown, although more recent studies have found that after neonatal immunization with HB vaccine, a large proportion of the children, especially adolescents, exhibited waning immunity. Such decreased protection poses the risk of breakthrough infection [3-5]. It is generally assumed that the long-term efficacy of HB vaccine depends primarily on peak antibody levels after vaccination. The study of McMahon et al. [6] revealed that children vaccinated in early childhood were more likely to have undetectable levels of hepatitis B 
surface antibody (anti-HBs) in late adolescence or young adulthood, when the risks for HB infection increase. Other studies have shown that lower seroconversion rates occurred in children after primary vaccination if they had received the vaccine immediately after birth [7-9].

Universal HB immunization began in 1998 in Turkey [10]. Children born to seronegative mothers were vaccinated according to the 2-4-9 (age in months) schedule between 1998 and 2002; thereafter, the vaccination schedule was changed to 0-2-9 months and remained so until 2007. Since 2008, the $0-1-6$ vaccination scheme has been applied [11]. The aim of this study was to compare the immunogenicity of $\mathrm{HB}$ vaccine administered in the two different vaccination schemes starting either at month 2 of life or at birth.

\section{Materials and methods}

\section{Subjects}

This descriptive cross-sectional study was performed at the Gazi University Faculty of Medicine Well-Child Clinic between June 2004 and June 2005. The study cohort consisted of all infants who made routine well-child visits to the clinic, whose parents gave informed consent for the study, and who fulfilled the following inclusion criteria: (1) age between 18 and 30 months; (2) made regular visits to the clinic for routine check-ups; (2) were born to hepatitis B surface antigen (HBsAg)-negative mothers; (4) showed no sign of chronic disease; (5) gestational age was $>37$ weeks and birth weight was $>2,000 \mathrm{~g}$; (6) primary hepatitis $\mathrm{B}$ vaccination program was completed in this clinic according to either the 0-2-9 or 2-4-9 schedule.

A total of 267 infants satisfied all inclusion criteria and were enrolled in the study. Of these, 111 infants received three doses of vaccine at months $0,2,9$ (group 1) and 156 infants received three doses of vaccine at months $2,4,9$ (group 2). Vaccines for diphtheria, pertussis, tetanus, and live polio were concomitantly given at the second and fourth months. Age and anti-HBs values of the mothers and gestational age, birth weight, and gender of the child were recorded on the well-child visit chart.

\section{Ethical aspects}

The study protocol was approved by the ethical committee of Gazi University Medical Faculty.

Vaccines

All infants were administered $0.5 \mathrm{ml}(10 \mu \mathrm{g})$ of Euvax B vaccine, which is provided in the form of 10-ml glass vials
(LG Life Sciences, Iksan-si, Korea). The vaccine contains $10 \mathrm{mg}$ purified HBsAg (Saccharomyces cerevisiae is produced by recombinant DNA technology in yeast cells), $0.25 \mathrm{mg}$ aluminum hydroxide gel, and $0.01 \%(\mathrm{w} / \mathrm{v})$ thiomersal. The vaccines were always stored at $2-8^{\circ} \mathrm{C}$ and given intramuscularly in the anterolateral thigh according to either of one of the vaccination schedules.

\section{Laboratory methods}

Hepatitis B surface antigen, anti-HBs, and hepatitis B core antibody (anti-HBc) were measured by enzyme-linked immunosorbent assays (ELISA) using commercial test kits (UniCel DxI 800 System; Beckman Coulter, CA) in accordance with the manufacturer's instructions. Anti-HBs is expressed in international units per liter (IU/L) after comparison with the WHO reference standard. The lower limit of detection for the ELISA was 5 IU/L. Serum samples were studied on the same day. All children with an anti-HBs concentration $\geq 10 \mathrm{IU} / \mathrm{L}$ were considered to be seroprotected.

\section{Statistical methods}

Statistical analysis was performed using SPSS ver. 15.0 software (SPSS, Chicago, IL). Descriptive values for continuous variables were given as the mean \pm standard deviation (SD), while categoric variables were expressed as number and percentage. All data were tested for normal distribution, and comparisons were made with parametric and nonparametric tests for normally distributed and nonnormally distributed variables, respectively. The Spearman correlation test was performed for the correlation analysis.

Anti-HBs concentrations were log-transformed prior to calculating the geometric mean titer (GMT). For analytic purposes, children with undetectable anti-HBs were assigned a value of $2.5 \mathrm{IU} / \mathrm{L}$. A $t$ test was used to compare the log-transformed peak anti-HBs concentrations, while proportions were compared using a chi-square tests. A $p$ value $<0.05$ was considered to be statistically significant.

\section{Results}

All 267 infants who participated in the study showed no evidence of HB infection. The mean age of the children was $23.22 \pm 2.36$ months (minimum 18, maximum 30, median 24 months). Duration after primary immunization and blood sampling for both groups was $14.22 \pm 2.36$ months (minimum 9, maximum 21 , median 15 months). The quantitative anti-HBs value for 12 mothers ( 1 in group 1,11 in group 2) could not be obtained because they were measured in another laboratory; these mothers were therefore 
excluded from the study. There were no significant differences between the two groups in terms of the age or the antiHBs GMT levels of the mothers, gestational age, mean interval between the last dose of $\mathrm{HB}$ vaccine and blood sampling, and birth weight or gender of the infants (Table 1).

There was no correlation between the anti-HBs levels of mothers and infants $(p=0.850)$.

Anti-HBs GMT levels of infants in group 1 and 2 were 95.00 and $379.51 \mathrm{IU} / \mathrm{L}$ respectively $(p=0.0001)$.

Figure 1 shows the frequencies of protective levels of anti-HBs after primary vaccination in the two different vaccination schemes. Anti-HBs levels $\geq 10 \mathrm{IU} / \mathrm{L}$ after primary vaccination in infants who received the first vaccination at month 2 (group 2) and at birth (group 1) were 99.4 and 90.1\%, respectively (Fisher's Exact test $p=0.0001)$.

In terms of long-term protection, anti-HBs levels $\geq 100 \mathrm{IU} / \mathrm{L}$ were considered to be important. In infants whose first dose of $\mathrm{HB}$ vaccination was received at 2 months of age, $94.9 \%$ had anti-HBs levels $\geq 100 \mathrm{IU} / \mathrm{L}$ after the primary vaccination, while in infants whose vaccination started at birth, this was only $57.7 \%$ (Fisher's Exact test $p=0.0001$ ). When factors associated with longterm protection were analyzed, prenatal anti-HBs level of the mother $(p=0.197)$, gestational age $(\leq 37$ weeks) $(p=0.576)$, and gender $(p=0.305)$ were statistically insignificant. Antibody titers $\geq 100 \mathrm{IU} / \mathrm{L}$ were 13.59 -fold higher in the infants of group 2 than in those of group 1 (odds ratio 13.59, 95\% confidence interval 5.77-33.14; $p=0.0001)$.

\section{Discussion}

Members of the medical profession consider an anti-HBs level $\geq 10 \mathrm{IU} / \mathrm{L}$ to be protective against HB infection [12]; in addition, an anti-HBs level $\geq 100 \mathrm{IU} / \mathrm{L}$ is taken as evidence of long-lasting immunity [13]. The duration of immunity after $\mathrm{HB}$ vaccination is currently unknown, but it is generally assumed that the higher the antibody levels after vaccination, the longer the period of protection [13-15]. Our study shows that although the vaccine was highly immunogenic in both of the vaccination schemes investigated, the scheme starting at the end of second month of life yielded a significantly higher immunogenicity than that starting at birth. Only limited data are currently available to compare alternate schedules against the conventional schedule, but our results do confirm those from a number of previous studies $[7,8,16]$. The subjects in these three studies were all infants of HBsAg-negative mothers, and the results showed that these infants had lesser seroconversion if they received the first dose of $\mathrm{HB}$ vaccine immediately after delivery instead of 2 months

Table 1 Characteristics of study groups

\begin{tabular}{|c|c|c|c|c|c|c|}
\hline & \multicolumn{2}{|c|}{ Group $1^{\mathrm{a}}(n=111)$} & \multicolumn{2}{|c|}{ Group $2^{\mathrm{b}}(n=156)$} & Total $(n=267)$ & $p$ \\
\hline \multicolumn{7}{|l|}{ Children } \\
\hline Mean age (months) & \multicolumn{2}{|l|}{$23.12 \pm 2.61$} & \multicolumn{2}{|c|}{$23.29 \pm 2.17$} & $23.22 \pm 2.36$ & 0.540 \\
\hline \multicolumn{7}{|l|}{ Gender $(n)$} \\
\hline Male & \multicolumn{2}{|l|}{60} & \multicolumn{2}{|l|}{75} & 135 & 0.336 \\
\hline Female & \multicolumn{2}{|l|}{51} & \multicolumn{2}{|l|}{81} & 132 & \\
\hline Gestational age (weeks) & \multicolumn{2}{|l|}{$38.68 \pm 1.07$} & \multicolumn{2}{|c|}{$38.71 \pm 1.16$} & $38.7 \pm 1.12$ & 0.813 \\
\hline Birth weight (g) & \multicolumn{2}{|l|}{$3,248 \pm 384.5$} & \multicolumn{2}{|c|}{$3,340 \pm 433.3$} & $3,301 \pm 415.4$ & 0.075 \\
\hline Mother's age (years) & \multicolumn{2}{|l|}{$29.01 \pm 4.6$} & \multicolumn{2}{|c|}{$29.66 \pm 4.5$} & $29.39 \pm 4.57$ & 0.259 \\
\hline Anti-HBs GMT (IU/L) & \multicolumn{2}{|l|}{95.00} & \multicolumn{3}{|l|}{379.51} & 0.0001 \\
\hline \multirow[t]{2}{*}{ Positive anti-HBs $(\%)^{\mathrm{c}}$} & \multirow[t]{2}{*}{90.1} & & \multicolumn{3}{|l|}{99.4} & 0.0001 \\
\hline & & Group & $=110)$ & Group 2 & Total $(n=255)$ & $p$ \\
\hline \multicolumn{7}{|l|}{ Mothers } \\
\hline \multicolumn{2}{|c|}{ Prenatal Anti-HBs GMT of mothers (IU/L) } & 6.349 & & 5.140 & & 0.297 \\
\hline \multicolumn{2}{|c|}{ Prenatal Anti-HBs titer $\geq 10$ IU/L of mothers $(\%)$} & 25.2 & & 25 & & 0.357 \\
\hline
\end{tabular}

GMT, Geometric mean titer; anti-HbBs, hepatitis B surface antibody

Where appropriate, data are given as the mean \pm standard deviation (SD)

${ }^{\text {a }}$ Group 1, infants who received three doses of hepitatis B (HB) vaccine at months 0, 2, 9 of life

${ }^{b}$ Group 2, infants who received three doses of $\mathrm{HB}$ vaccine at months 2, 4, 9 of life

c Anti-HBs $>10 \mathrm{IU} / \mathrm{L}$ 


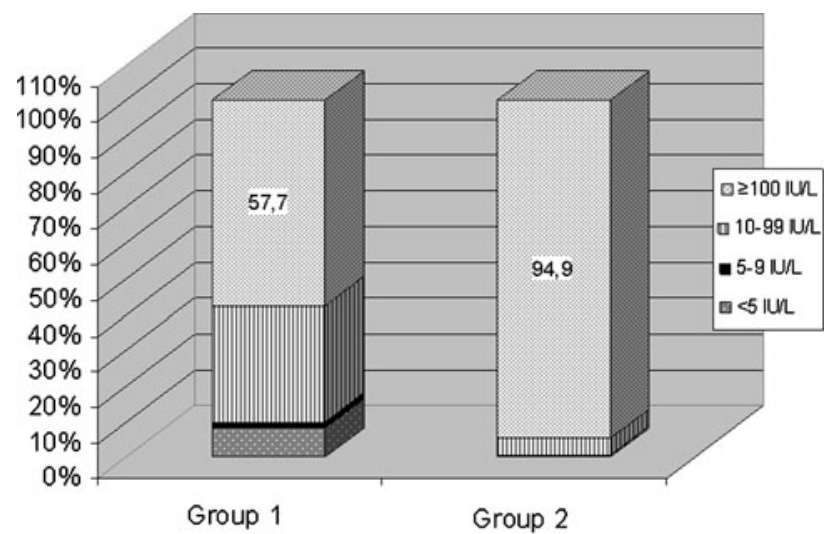

Group 1: infants who received three doses of $\mathrm{HB}$ vaccine at months $0,2,9$ Group 2: infants who received three doses of $\mathrm{HB}$ vaccine at months $2,4,9$

Fig. 1 Immunological responses in two different Hepatitis B vaccination schedules

after birth. In another study on the protective effects of $\mathrm{HB}$ vaccine in infants of HBsAg-positive mothers who were followed up for 36 months, HB infections were observed to be more frequent in infants whose vaccination started at birth [17], likely due to the insufficient maturation of the immune system in newborn infants. Furthermore, maternally derived antibodies can interfere with active immunization. Weeratna et al. [18] showed that B cell responses remained weak when newborn mice were immunized against HBsAg in the presence of high levels of maternal antibody against HBsAg, and $\mathrm{Hu}$ et al. [19] showed that passively acquired maternal anti-HBs in infants may, to some extent, impair the antibody response to $\mathrm{HB}$ vaccine. In our study, there were no differences between the antiHBs levels of mothers of the two groups in pregnancy, whereas infants showed lower seroconversion if they received the first dose of $\mathrm{HB}$ vaccine immediately after delivery. We consider the immunological immaturity of the newborn to be the predicting factor of antibody levels in the postvaccination period.

A number of studies have shown that persistence of HBs antibodies is not long term in babies who are vaccinated at birth. In two studies of children 5-6 years after they had received the primary vaccination with recombinant $\mathrm{HB}$ vaccine, Petersen et al. [20] found that $12.5 \%$ and Seto et al. [21] found that $19 \%$ of the children had protective levels of anti-HBs antibodies. In comparison, West et al. [22] found that the anti-HBs titer was $\geq 10$ after 12 years in all of the children vaccinated with plasma-derived HB vaccine $2-3$ months after birth.

Stevens et al. [9] showed that the immune response was enhanced by delaying the initial injection to 1 month after birth and the third injection to 6-9 months of age. A number of authors reported that in their studies the concentrations of anti-HBs after the third injection were dependent on the interval between the second and the third dose. Children receiving the third vaccine dose relatively late developed antibody titers higher than those receiving the third dose on schedule [13, 14, 23]. In our study, the interval between the second and third doses for those infants vaccinated at birth was longer than that for infants vaccinated at the second month, but we did not observe any positive impact of this difference on antibody levels.

At the present time, there are no assays to measure correlates of protection against HB infection directly [24]. It is therefore possible that immunological memory itself depends on the development of a protective level of antibodies after vaccination. However, there is a strong belief that a high proportion of children vaccinated in early childhood retain immune memory and develop an anti-HBs response upon exposure to HB later in life. Thus, even if anti-HBs concentrations decline to $<10 \mathrm{IU} / \mathrm{L}$, immune memory would continue to persist over a longer time [1, 25]. It is likely that vaccinated children born to HBsAgpositive mothers or living in areas where $\mathrm{HB}$ infection is endemic are exposed to HB throughout childhood. Such children can obtain natural booster doses. However, the duration of immunity among children born to HBsAgnegative mothers or those living in low endemicity settings may be shorter due to the absence of natural boosting. Turkey is known to have moderate HB endemicity [26]; thus children born to HBsAg-negative mothers need longterm protectivity. If immunological memory may later decline or become undetectable, the risk of breakthrough infection may occur. Some countries have chosen not to implement immunization at birth and instead screen pregnant women for HBsAg [27]. The HB vaccine birth dose is then given only to infants born to $\mathrm{HBsAg}$-positive mothers. In our country, the initial vaccination for infants born to HBsAg-negative mothers (in many metropolises HB markers can be screened) may be delayed until a few months after birth, the first vaccination time of other routine infant vaccine antigens (DaPT-IPV-Hib and conjugated pneumococcus). This vaccination can be easily performed in combination with other vaccines, thus reducing the number of required injections, simplifying administration and improving immunization rates. Screening also enables medical professionals to identify HB carriers, thereby providing an opportunity to give HB immunoglobulin to infants born to these mothers. However, screening is costly and not usually feasible in developing countries. In countries where screening programs for pregnancy are not available, vaccination at birth for HB perinatal infections is still a necessity. However, such infants should be followed up to evaluate whether or not they will have long-term immunity. Our study is a preliminary report, and we plan to follow up these infants until puberty and evaluate their immunological status. 


\section{Conflict of interest statement None.}

Open Access This article is distributed under the terms of the Creative Commons Attribution Noncommercial License which permits any noncommercial use, distribution, and reproduction in any medium, provided the original author(s) and source are credited.

\section{References}

1. Van Herck K, Van Damme P. Benefits of early hepatitis B immunization programs for newborns and infants. Pediatr Infect Dis J. 2008;27:861-9.

2. Demirjian A, Levy O. Safety and efficacy of neonatal vaccination. Eur J Immunol. 2009;39:36-46.

3. Lu CY, Chiang BL, Chi WK, Chang MH, Ni YH, Hsu HM, Twu SJ, Su IJ, Huang LM, Lee CY. Waning immunity to plasmaderived hepatitis $\mathrm{B}$ vaccine and the need for boosters 15 years after neonatal vaccination. Hepatology. 2004;40:1415-20.

4. Bialek SR, Bower WA, Novak R, Helgenberger L, Auerbach SB, Williams IT, Bell BP. Persistence of protection against hepatitis $B$ virus infection among adolescents vaccinated with recombinant hepatitis B vaccine beginning at birth: a 15-year follow-up study. Pediatr Infect Dis J. 2008;27:881-5.

5. Hammitt LL, Hennessy TW, Fiore AE, Zanis C, Hummel KB, Dunaway E, Bulkow L, McMahon BJ. Hepatitis B immunity in children vaccinated with recombinant hepatitis B vaccine beginning at birth: a follow-up study at 15 years. Vaccine. 2007;25:6958-64.

6. McMahon BJ, Bruden DL, Petersen KM, Bulkow LR, Parkinson AJ, Nainan O, Khristova M, Zanis C, Peters H, Margolis HS. Antibody levels of protection after hepatitis B vaccination: results of a 15-year follow-up. Ann Intern Med. 2005;142:333-41.

7. del Canho R, Grosheide PM, Voogd M, Huisman WM, Heijtink RA, Schalm SW. Immunogenicity of 20 micrograms of recombinant DNA hepatitis B vaccine in healthy neonates: a comparison of three different vaccination schemes. J Med Virol. 1993;41:30-4.

8. Bassily S, Kotkat A, Gray G, Hyams KC, Brown FM, Imam IZ, Arthur R. Comparative study of the immunogenicity and safety of two dosing schedules of hepatitis B vaccine in neonates. Am J Trop Med Hyg. 1995;53:419-22.

9. Stevens CE, Toy PT, Taylor PE, Lee T, Yip HY. Prospects for control of hepatitis B virus infection: implications of childhood vaccination and long-term protection. Pediatrics. 1992;90:170-3.

10. Turkish Ministry of Health. Circular about extended program of immunization no: 1998/6856. Ankara: Turkish Ministry of Health.

11. Turkish Ministry of Health. Circular about extended program of immunization no: 2009/7941. Ankara: Turkish Ministry of Health.

12. Szmuness W, Stevens CE, Zang EA, Harley EJ, Kellner A. A controlled clinical trial of the efficacy of the hepatitis B vaccine (Heptavax B): a final report. Hepatology. 1981;1:377-85.

13. Hadler SC, de Monzon MA, Lugo DR, Perez M. Effect of timing of hepatitis B vaccine doses on response to vaccine in Yucpa Indians. Vaccine. 1989;7:106-10.
14. Jilg W, Schmidt M, Deinhardt F. Vaccination against hepatitis B: comparison of three different vaccination schedules. J Infect Dis. 1989;160:766-9.

15. Scheiermann N, Gesemann M, Maurer C, Just M, Berger R. Persistence of antibodies after immunization with a recombinant yeast-derived hepatitis B vaccine following two different schedules. Vaccine. 1990;8:44-6.

16. Das RR, Mathew JL, Ratho RK, Dutta S. Randomized clinical trial comparing hepatitis $\mathrm{B}$ vaccine administered by 0,6 , and 14 week versus 6,10 , and 14 week schedule in healthy infants. J Trop Pediatr. 2009;55:328-31.

17. Schalm SW, Mazel JA, de Gast GC, Heijtink RA, Botman MJ, Bänffer JR, Cerards LJ, Zwijnenberg J, Fetter WP, Nuijten SM, Wladimiroff YW, Chritensens CML. Prevention of hepatitis B infection in newborns through mass screening and delayed vaccination of all infants of mothers with hepatitis B surface antigen. Pediatrics. 1989;83:1041-8.

18. Weeratna RD, Brazolot Millan CL, McCluskie MJ, Siegrist CA, Davis HL. Priming of immune responses to hepatitis B surface antigen in young mice immunized in the presence of maternally derived antibodies. FEMS Immunol Med Microbiol. 2001;30: 241-7.

19. Hu Y, Wu Q, Xu B, Zhou Z, Wang Z, Zhou YH. Influence of maternal antibody against hepatitis $B$ surface antigen on active immune response to hepatitis B vaccine in infants. Vaccine. 2008;26:6064-7.

20. Petersen KM, Bulkow LR, McMahon BJ, Zanis C, Getty M, Peters H, Parkinson AJ. Duration of hepatitis B immunity in low risk children receiving hepatitis $\mathrm{B}$ vaccinations from birth. Pediatr Infect Dis J. 2004;23:650-5.

21. Seto D, West DJ, Ioli VA. Persistence of antibody and immunologic memory in children immunized with hepatitis B vaccine at birth. Pediatr Infect Dis J. 2002;21:793-5.

22. West DJ, Watson B, Lichtman J, Hesley TM, Hedberg K. Persistence of immunologic memory for twelve years in children given hepatitis B vaccine in infancy. Pediatr Infect Dis J. 1994;13:745-7.

23. Girisha KM, Kamat JR, Nataraj G. Immunological response to two hepatitis B vaccines administered in two different schedules. Indian J Pediatr. 2006;73:489-91.

24. Mathew JL, El Dib R, Mathew PJ, Boxall EH, Brok J. Hepatitis B immunisation in persons not previously exposed to hepatitis B or with unknown exposure status. Cochrane Database Syst Rev. 2008;16:CD006481.

25. European Consensus Group on Hepatitis B. Immunity are booster immunisations needed for lifelong hepatitis B immunity? Lancet. 2000;355:561-5.

26. Mast EE, Weinbaum CM, Fiore AE, Alter MJ, Bell BP, Finelli L, Rodewald LE, Douglas JM Jr, Janssen RS, Ward JW. Advisory Committee on Immunization Practices (ACIP). A comprehensive immunization strategy to eliminate transmission of hepatitis B virus infection in the United States: recommendations of the Advisory Committee on Immunization Practices (ACIP) part 1: immunization of infants, children, and adolescents. MMWR Recomm Rep. 2005;54(RR-16):1-31.

27. EUROHEP.NET. Recommendations for hepatitis B prevention strategies. Available at: www.eurohep.net. Accessed 22 March 2010. 